\title{
Deposition of titanium nitrides composite ceramic coating by reactive plasma spraying method
}

\author{
Ming Xia ${ }^{1, a}$, Zehua Wang ${ }^{1}$, Zehua Zhou ${ }^{1}$, Yaqun $\mathrm{Hu}^{1}$, Huan Sheng ${ }^{1}$ \\ ${ }^{1}$ College of Mechanics and Materials, Hohai University,Nanjing,210098,China \\ aemail: xiaming422@126.com
}

Keywords: coatings; reactive plasma spraying; deposition

\begin{abstract}
Titanium nitrides composite ceramic coatings are a material which possesses high mechanical properties, being often used in order to protect the substrate thus increasing their lifetime and also working in harsh environments.In this study, the paper presents the experimental results on deposition of titanium nitrides composite ceramic coatings by reactive plasma spraying. In this way the advantages of the method is achieving high high hardness, obtaining improving quality coatings in the same time getting high productivity. Commercially pure titanium feedstock was used. The microstructure of the coating investigated both by optical and scanning electron microscopy shows that the coatings are dense and obvious lamellae structure. Surface roughness of the coating is about $3.259 \mu \mathrm{m}$.Vickers microhardness of the coating presents average values of 1444.1 $\mathrm{Hv}_{0.1}$.
\end{abstract}

\section{Introduction}

Thermal spraying is a well-established technique for application of coatings.And this process encompasses a range of coating technique when molten or semi-molten droplets of a coating material are accelerated toward a substrate[1]. In recent years, increasing needs in ceramic coatingd contributed to the rise use of thermal spraying. One of the interesting thermal spraying technique is reactive plasma spraying(RPS). Reactive plasma spraying technique allows the deposition of in situ formed composite coatings, with a hard ceramic phase microdispersed in a metallic[2], as well as its flexibility, high deposition rates and multifunction[3].

Titanium nitrides composite ceramic coatings have gained much attention recently due to its low friction coefficient, high hardness, high melting point, excellent chemical stability and wear reaistance[4], being used for coating the cutting tools to increase their lifetime.Titanium nitrides composite ceramic coatings can be obtained by various methods such as laser, reactive plasma spraying,PVD(physical vapor deposition) and CVD(chemical vapor deposition)[5]. However, there is a fatal disadvantage of PVD and CVD methods that the coating is thin.Reactive plasma spraying is often used for the deposition of titanium nitrides composite ceramic coatings with high quality[6] which presenting several advantages in comparison with the CVD and PVD methods, namely: the thickness can be higher and the deposited layers present high toughness, which will provide adequate strength of the layer to shocks which can occur during the operation.

However,few studies on reactive plasma spraying titanium nitrides composite ceramic coatings have been reported.Therefore, in this paper,the study are focused on the fabrication of titanium nitrides composite ceramic coatings with in situ synthesized titanium nitrides by reactive plasma spraying.The microstructure and the surface morphology of the coating is tested using optical microscopy(OM), scanning electron microscopy(SEM), energy disperdive spectroscopy (EDS) and $\mathrm{X}$-ray diffraction $(\mathrm{XRD})$.

\section{Experiment}

Commercially pure titanium feedstock was used for the deposition of titanium nitrides composite ceramic coatings. The characteristics of the experimental raw materials are shown in Table1.As substrate, a commom untreated low carbon steel 45 was used. Before the spraying process, 
rectangular samples were degreased with acetone and blasted with alumina to eliminate the impurities on the surface and to confer a surface roughness for better adhension. Titanium nitrides composite ceramic coatings were achieved using Tafa 3710 Praxair USA atmosphere plasma spraying system. The primary gas was argon,the powder carrier gas was nitrogen and the substrates were cooled with air after spraying. The main spraying parameters are presented in Table2.

Table 1 Compositions of titanium powder

\begin{tabular}{ccccccccc}
\hline Elements & $\mathbf{T i}$ & $\mathbf{F e}$ & $\mathbf{S i}$ & $\mathbf{C l}$ & $\mathbf{C}$ & $\mathbf{N}$ & $\mathbf{O}$ & $\mathbf{H}$ \\
\hline Ratio/wt.\% & 99.6 & 0.027 & 0.014 & 0.022 & 0.008 & 0.015 & 0.30 & 0.019 \\
\hline
\end{tabular}

Table2 Plasma spraying parameters

\begin{tabular}{|c|c|c|c|c|c|c|c|}
\hline $\begin{array}{l}\text { Primary } \\
\text { gas } \\
\text { Ar/ } \\
\text { L.min }{ }^{-1} \\
\end{array}$ & $\begin{array}{c}\text { Carrier } \\
\text { gas } \\
\mathrm{N}_{2} / \mathrm{L} \cdot \mathrm{mi} \\
\mathrm{n}^{-1} \\
\end{array}$ & $\begin{array}{l}\text { Auxiliary } \\
\text { gas } \\
\text { He/L.min }\end{array}$ & $\begin{array}{c}\text { Current } \\
\text { /A }\end{array}$ & $\begin{array}{c}\text { Voltage } \\
\text { /V }\end{array}$ & $\begin{array}{l}\text { Powder } \\
\text { feed rate } \\
\text { / g.min }{ }^{-1}\end{array}$ & $\begin{array}{l}\text { Sprayi } \\
\text { ng } \\
\text { distanc } \\
\text { e /mm } \\
\end{array}$ & $\begin{array}{c}\text { Gun } \\
\text { transversal } \\
\text { speed/ } \\
\mathrm{mm} \cdot \mathrm{s}^{-1} \\
\end{array}$ \\
\hline 60.5 & 6.62 & 16.5 & 745 & 46 & 22 & 140 & 150 \\
\hline
\end{tabular}

The titanium nitrides composite ceramic coatings were successfully prepared through reactive plasma spraying.The surface roughness was measured by JB-4C roughness tester.The microhardness was carried out by HXD-1000TC microhardness tester.The surface morphology and microstructure of the coating were observed by means of Hirox-7700 Digital Microscope(SM),Olympus BX51M microscope(OM) and Hitachi S-3400N Scanning electron microscopy (SEM) respectively.The distribution of chemical elements was ascertained with Horiba EX-250 energy dispersive spectromrter(EDS).The average porosity was evaluated by means of TD2000 image analysis method.

\section{Results and discussions}

Cross-sectional optical micrographs and porosity values obtained by image analysis. Fig. 1 shows the OM images of the cross section of the coating. It can be noticed from Fig. 1 that the coatings are continuous and dense, but have a high porosity which is a fatal defect of plasma spraying.The particles was heated- moltened and deposited on the substrate.It is inevitable forming pores between particles and layers.The thickness of the coating is approximately $400 \mu \mathrm{m}$.Besides,an obvious lamellae structure can be seen in the image at higher magnifications.

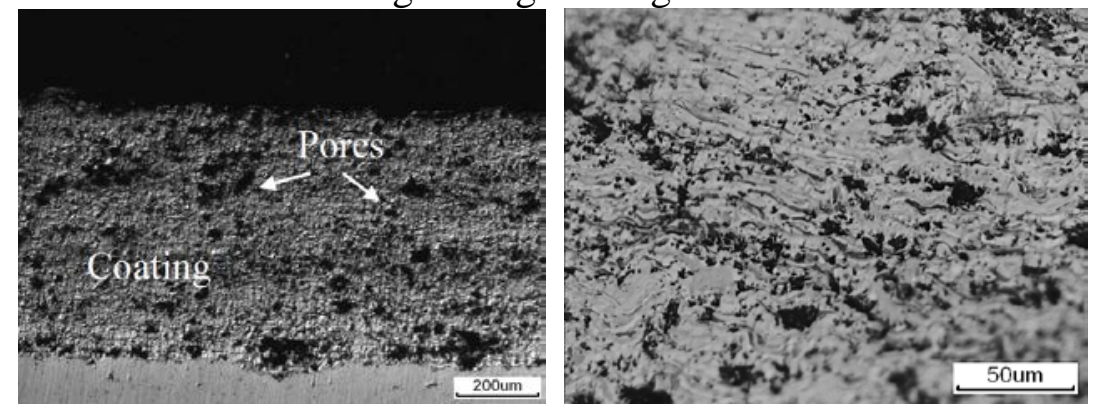

Fig.1 Cross section of titanium nitride composite coatings

Fig.2 presents the SEM images of titanium nitrides composite ceramic coatings deposited by reactive plasma spraying. It can be observed from Fig.2 that the coatings are rough and consist of flattened particles which have resulted from melting of titanium.Also,it can be seen at higher magnifications that the coatings consist of unmolten particles as well as microcracks. These defects may have a bad impact on the properties of the coatings,so it is necessary to optimize the parameters in order to improve the quality of the coating in the future. 

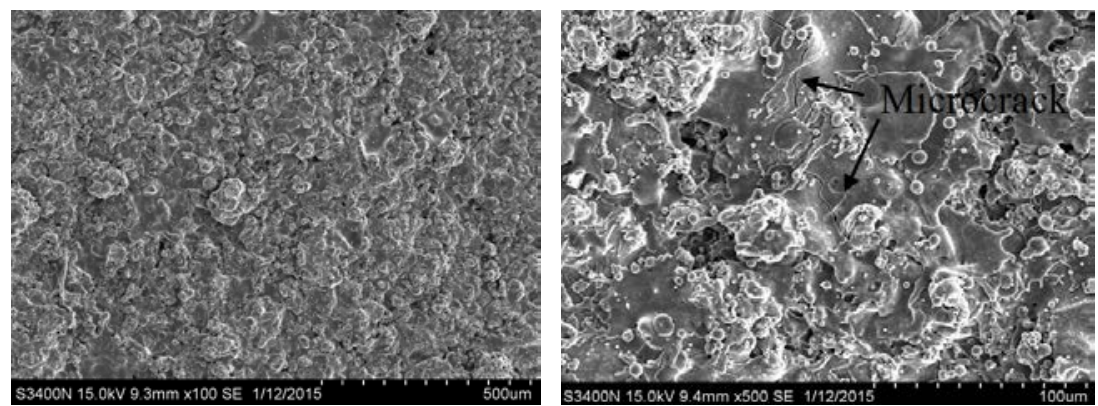

Fig.2 SEM images of titanium nitride composite coatings

As a crucial parameter to evaluate the quantity of the coating,the surface roughness was measured by JB-4C roughness tester. Fig.3 shows the roughness(a) and the Hirox-7700 Digital Microscope image of titanium nitride composite coatings.From Fig.3(a),it can be found that the value of the roughness $\mathrm{Ra}$ is about $3.259 \mu \mathrm{m}$ which is a little high. And from Fig.3(b),it can not be ignored that the ups and downs of the coatings which proves the analysis of Fig.3(a). This is consistant with the morphlogy of the titanium nitride composite coatings(as is seen from Fig.2)
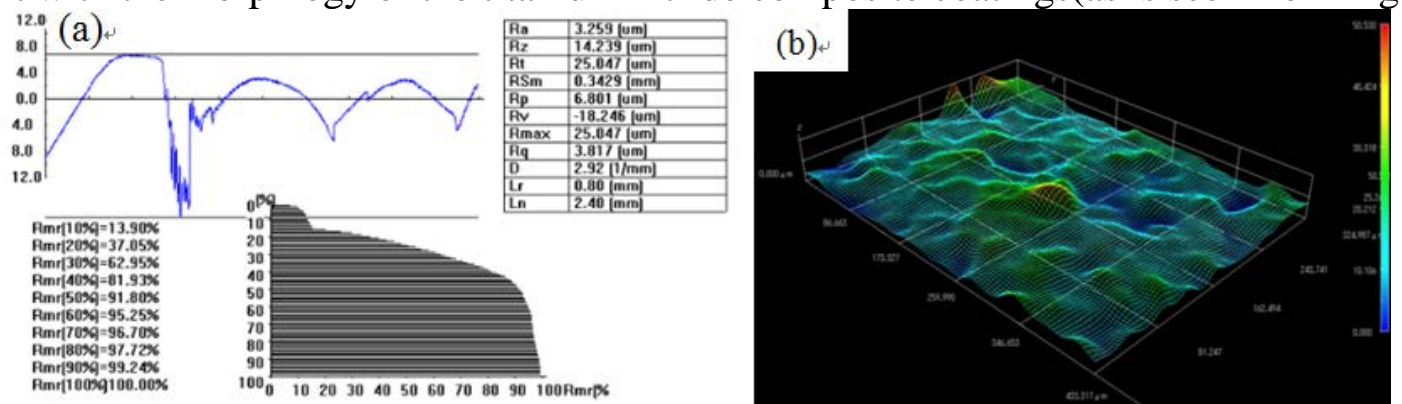

Fig.3 Images of roughness(a) and SM(b) of titanium composite coatings

Microhardness of the coatings was measured at two regions, that is ,every $50 \mu \mathrm{m}$ away from the coating surface and every $50 \mu \mathrm{m}$ away from the substrate.The microhardness of the coating is measured by HXD-1000TC microhardness tester. From the results,it can be noticed that the microhardness is fluctuant as well. The phenomenon may be owing to the presence of pores and microcracks.The values are ranging from 1219 to $1704.9 \mathrm{Hv}_{0.1}$ and the average is $1444.1 \mathrm{Hv}_{0.1}$ which is 5 times of the substrate $\left(288 \mathrm{Hv}_{0.1}\right)$. The high microhardness of the coating is attributed to the presence of hard phases.

\section{Conclusions}

Titanium nitrides composite ceramic coatings were successfully prepared on the carbon steel substrate by reactive plasma spraying.The microstructure ,the roughness and the microhardness were studied,and the conclusions were dropped as follows:

(a) The titanium nitrides composite ceramic coatings are continuous and dense.

(b)The coating has a typical lamellae structure.There is a fatal defect of reactive plasma spraying titanium nitrides composite ceramic coatings that the porosity is high. The surface of the coating is rough.

(c) The reactive plasma spraying titanium nitrides composite ceramic coatings have a high microhardness.

\section{Acknowledgments}

This work was financially supported by the National Natural Science Foundation of China(Grant No.51379070), and Postgraduates research and innovation projects (CXZZ13-02). 


\section{Reference}

[1] S.J.Matthews,B.J.James,M.M.Hyland. Microstructural influence on erosion behavior of thermal spray coatings[J].Materials Characterization,2007,58(1):59-64.

[2] F.Borgioli,E.Galvanetto,F.P.Galliano,T.Bacci. Sliding wear resistance of reactive plasma sprayed Ti-TiN coatings[J].Wear,260(2006):832-837.

[3] M.M.Verdian, M. Salehi, K. Raeissi. Influence of feedstock particle size on corrosion resistance of air plasma sprayed NiTi coatings applied to AISI 1045 steel [J]. Surface Engineering, 2010, 26(6): 478-483.

[4] D Munteanu.C Gabor.D G Constantin.Friction and wear behviors of Ti(C.O.N) dark decorative coatings. Tribology Interational,44(2011)820-828

[5] H.Tahara,Y.Ando.Study of titanium nitride deposition by supersonic plasma spraying [J].Vacuum, 83(2009):98-101.

[6] D.Zou,D.Yan,L.Xiao,Y.Dong. Characterization of nanostructured TiN coatings fabricated by reactive plasma spraying[J]. Surface and Coating Technology, 202(2008)1928-1934. 